\title{
Editor Note: Medical Microbiology \& Diagnosis
}

Joel K Weltman *

Alpert Medical School, Brown University, USA

*Corresponding author: Joel K Weltman, Clinical Professor Emeritus of Medicine, Alpert Medical School, Brown University, Providence, RI 02912, USA, Tel No: 401-2457588; E-mail: joel_weltman@brown.edu

Rec Date: Jun 23, 2016; Acc Date: Jun 24, 2016; Pub Date: Jun 27, 2016

Copyright: ( 2016 Weltman JK. This is an open-access article distributed under the terms of the Creative Commons Attribution License, which permits unrestricted use, distribution, and reproduction in any medium, provided the original author and source are credited.

\section{Editorial}

The current issue (Volume 5, Issue 2) of JMMD contains 12 articles, which consist of seven research articles, one case report, three editorials and one review article. For your convenience, below are a few words to let you know what I think you can expect from each of these articles.

Research by Pillai and mini studied polysaccharides are potential candidates for development of vaccines. In this research, capsular polysaccharide virulence factor of Pasteurella multocida (DP1) was isolated and structurally characterized by infrared (IR) spectroscopy and by nuclear magnetic resonance (NMR) spectroscopy. This analysis will help facilitate anti-Pasteurella vaccine design [1].

Research by El-Banna et al. studied the effects of antihistamine drugs on adaptations of Gram-negative bacteria to resist antimicrobial agents were investigated. Marked synergism was detected in multidrug resistant (MDR) Klebsiella pneumoniae isolates when the ethanolamine antihistaminic, diphenhydramine, was used in combination with a variety of antibiotics such as azithromycin, erythromycin, amikacin, gentamicin or ciprofloxacin. This information can be useful in the treatment of infectious diseases, especially in this era of emerging multi-drug resistant strains [2].

In leprosy, the lepromatous form of the disease is more severe and results from suppression of host $\mathrm{T}$ cell response. $\mathrm{T}$ regulatory cells, which suppress the $\mathrm{T}$ cell response, have been found in greater frequency in the blood of leprosy patients and at the site of leprosy infection. The present study was carried out to evaluate the role of Mycobacterium leprae antigen phenolic glycolipid 1 (PGL-1) in the induction of $\mathrm{T}$ regulatory cells in leprosy patients were well described by Bhavyata Dua [3].

Dilnessa et al. discussed that approximately 20 million cases of severe sepsis occur each year throughout the world. Blood cultures play a major role in the diagnosis and management of those infections. This article reviews the principles, technical requirements and limitations of current blood-culture techniques [4].

Weltman investigated the design and production of an anti-Zika virus (ZIKV) vaccine is important because of the association of infection by ZIKV with microcephaly in the developing fetus. Reported here is a bio-informatic analysis of the ZIKV envelope E protein based on both Shannon entropy and B cell epitope prediction. This analysis aims to identify loci within ZIKV E protein with the potential to serve as targets for protective anti-ZIKV vaccines [5].

Editorial by Kandi provides an overview of human infections caused by Bacillus species other than Bacillus anthracis and the reasons for their probable under-reporting. It is suggested that many clinical microbiology laboratories ignore these bacteria as laboratory contaminants and that careful clinical and laboratory evaluations are required in order to determine the actual role of Bacillus species bacteria in causing infections in humans [6].

Another Editorial by Zaghloul discussed about the emergence of strains of Staphlococcus aureus bacteria that are resistance to methicillin (MRSA) has become a global problem. The rapid and accurate detection of MRSA is essential for the clinical management and treatment of MRSA-infected patients. This article is a concise, insightful and clinically useful overview of the biological principles underlying the MRSA problem [7].

Editorial by Molina and Basualdo explained about the global review of ZIKV from Argentina, where human-to-human transmission, but not mosquito-to human transmission of the virus has been observed. This publication considers ZIKV epidemiology from both regional and global points of view [8].

Case Report by Henry et al. studied about two hepatic cysts, one in a man with chronic hepatitis B, another in a woman with nonHodgkin's lymphoma. One of the cysts undergoes spontaneous regression but the other undergoes repeated aspirations without benefit [9].

The strictly anaerobic, spore-forming, Gram positive bacterium Clostridium difficile is a leading cause of healthcare-associated infections. This study demonstrates that when C. difficile cells are exposed to germination solutions that contain the bile salt sodium taurocholate, those vegetative cells tend to undergo prolonged germination on the surfaces they contaminate. The germinating $\mathrm{C}$ difficile cells thus become susceptible to disinfectants applied to the contaminated surfaces. This research presents an original approach to the prevention of the $\mathrm{C}$ difficile infections that tend to occur in the healthcare environment which is well described by Worthington Tand Hilton Ac [10].

Research Article by Tarhan, et al. described that the COBAS Amplicor is an automated PCR system for the rapid detection of RNA and DNA target sequences. This article addresses the use of various decontamination-homogenization-concentration techniques to enable the timely identification of the Mycobacterium tuberculosis complex (MTBC) in clinical samples using the COBAS Amplicor. Such timely identification plays an important role in the control of the spread of tuberculosis and its effective treatment [11].

Research Article by Walid, et al. is a retrospective cohort study of 122 children (age less than 1 year to age 18 years) with various pulmonary, other respiratory and optic infections. The children were treated within a 5-year interval (Jan 2009 to Jan 2015) at the King Abdulaziz University Hospital, a teaching hospital situated in Jeddah, Saudi Arabia. Reported is a laboratory and statistical analysis of the emergence of antibiotic resistance in the numerous types of microorganisms that were isolated. This study helps to contribute to $t$ 
Page 2 of 2

understanding of the proper use of antibiotics in the treatment of infectious diseases [12].

\section{References}

1. Pillai TG, Mini M (2016) Bacterial polysaccharides - potential candidate for vaccine development. J Med Microb Diagn 5: 224

2. El-Banna TES, Sonbol FI, El-Aziz AAA, Al-Fakharany OM (2016) Modulation of antibiotic efficacy against klebsiella pneumoniae by antihistaminic drugs. J Med Microb Diagn 5: 225.

3. Dua B, Sharma B, Chakma JK, Arora M, Bhadauria R, et al. (2016) Expansion of $t$ regulatory cells in lepromatous leprosy is mediated by phenolic glycolipid-1. J Med Microb Diagn 5: 226.

4. Dilnessa T, Demeke G, Mengistu G, Bitew A (2016) Emerging blood culture technologies for isolation of blood pathogens at clinical microbiology laboratories. J Med Microb Diagn 5: 227.

5. Weltman JK (2016) An immuno-bioinformatic analysis of zika virus (zikv) envelope e protein. J Med Microb Diagn 5: 228.
6. Kandi V (2016) Clinical significance of bacillus species other than bacillus anthracis. J Med Microb Diagn 5: e130.

7. Zaghloul MZ (2016) Methicillin-resistant staphylococcus aureus (mrsa). J Med Microb Diagn 5: e131.

8. Molina NB, Basualdo JA (2016) Zika virus in the americas: a new global health emergency. J Med Microb Diagn 5: e132.

9. Henry CH, Dargan A, Deshmukh S, Hann HW (2016) A tale of two cysts: disparate outcomes of two hepatic cysts. J Med Microb Diagn 5: 229.

10. Worthington T, Hilton AC (2016) Sporulation of clostridium difficile in aerobic conditions is significantly protracted when exposed to sodium taurocholate. J Med Microb Diagn 5: 230

11. Tarhan G, Saygan MB, Cesur S, Ocak F, Ceyhan I (2016) The effect of three decontamination methods on cobas amplicor mycobacterium tuberculosis pcr assay. J Med Microb Diagn 5: 231.

12. Walid J, Moshref L, Alzanbagi M, Moshref R, Baabdullah W, et al. (2016) Antibiotic resistance pattern in healthy children diagnosed with community acquired respiratory tract infections in king abdulaziz university hospital. J Med Microb Diagn 5: 232. 